\title{
COPERNICUS AND THE ENERGY CHALLENGE
}

\author{
Lorenzo Stucchi ${ }^{1, *}$, Martina Aiello $^{2}$, Alessia Gargiulo $^{2}$, Maria Antonia Brovelli $^{1}$ \\ ${ }^{1}$ Politecnico di Milano, Department of Civil and Environmental Engineering, Piazza Leonardo da Vinci, 20133 Milano, Italy \\ ${ }^{2}$ Ricerca Sistema Energetico-RSE SpA, Milan, Italy \\ (lorenzo.stucchi, maria.brovelli)@polimi.it (martina.aiello, alessia.gargiulo)@ rse-web.it
}

Commission IV, WG IV/4

KEY WORDS: Open Geospatial Software, Open GIScience, Open Geospatial Data, Copernicus, Renewable Energy

\begin{abstract}
:
The energy sector will drastically change in the following years; multiple agreements have been signed by countries with the purpose to reduce carbon emission and contain the global temperature increase. Besides, in the next years the energy demand will increase with the growth of the Information and Communications Technology sector. To combine these two aspects, future energy needs to be produced with renewable resources and less with fossil fuels. An opportunity to discover and plan the use of renewable energy resources are geospatial data derived from satellite acquisitions. The European Earth Observation programme Copernicus provides multiple datasets in an Open Science approach. Within this paper, multiple datasets offered by Copernicus services are presented in relation to their exploitation for the energy system analysis, with a particular attention to renewable energy. The datasets will be analysed according to their properties and possibility of usage. Additional Copernicus satellite derived data that can benefit the emerging topic of the food-energy-water nexus are finally presented to point out significant development in the energy sector which is recently claiming growing attention.
\end{abstract}

\section{INTRODUCTION}

In 2015 the Paris Agreement was signed by 196 Parties with the purpose to keep the increase in global average temperature to well below two Celsius degrees above the pre-industrial levels. In 2019, the European Commission proposed the new European Green Deal, supported the creation of "An Open, Democratic and Sustainable Society", and stated the necessity of reaching climate-neutrality by 2050 . But, as reported in the plan, the energy demand will grow in the coming years due to the increase in the ICT sector.

These two requests can be satisfied only with the use of renewable energy, which is based on natural resources, such as sunlight, wind, rain, waves, geothermal heat and biomass and the drastic reduction of the energy produced by burning fossil fuels such as oil, coal and gas. Being the energy question one of the most challenging, geospatial experts are active in exploring how they can contribute to this field. The use of data provided by satellites offers a relevant opportunity to this aim. Copernicus data have been successfully used in some past research, but its full potential has not been completely exploited.

In 2019, the Copernicus data were used to create online monitoring and estimation application SEAP (Solar Energy Assessment and Planning) (Moreno-Garcia et al., 2019) for photovoltaic production. The tool interrogated the API of the climate data store (CDS) of the Copernicus Climate Change Service and could determine the energy produced, also providing forecasts from short-term to long-term to climate change conditions. The studies use climate variables of the solar radiation, air temperature at soil level, wind speed at soil level and precipitation. The data are provided with sub-daily (6h) and daily periods. Also, the authors use historical data to calibrate the application.

\footnotetext{
* Corresponding author
}

The potential in tidal energy in the Moroccan Atlantic Ocean and the Mediterranean Sea has been analysed by (Hariss et al., 2020). The research used the dataset from the Copernicus Marine Environment Monitoring Service of the Iberia-BiscayIreland Regional Seas. The dataset provided multiple pieces of information on physics, biogeochemistry and waves. The results of the research show the potential of the coasts as a source of renewable energy.

These examples show how the Copernicus data could be used for different approaches. The data could provide an introductory analysis as in the latter research. Either, they could also provide a final service to the plants' managers for technical management. Copernicus provides multiple other services that could be useful for other renewable energy sectors. The scope of the paper is to illustrate and describe the most interesting ones found in the different services.

The paper is structured in the following way. Section 2 presents the Copernicus program and the available services. Section 3 contains the current data usage in the energy sector. Section 4 describes the analysis technique, provides details on some relevant databases present in the Copernicus program. Section 5 presents the possible future development of the usage of the Copernicus and satellite data in the emerging themes in the energy sector. Section 6 concludes the paper by discussing the results.

\section{COPERNICUS PROGRAM}

Copernicus is the European Earth Observation Programme for monitoring the Earth. It delivers data and services based on satellite acquisitions and in situ measurements with free and open-source access. The Copernicus programme is composed of the infrastructure and six thematic services (Copernicus, 2021a), as shown in Figure 1. The services are: 
- the Copernicus Atmosphere Monitoring Service (CAMS) provides monitoring of air quality, climate forcing, renewable energy forces and greenhouse gases emissions;

- the Copernicus Marine Environment Monitoring Service (CMEMS) includes the observation for water quality, ocean forecasting and marine safety and transport;

- the Copernicus Land Monitoring Service (CLMS) includes the monitoring for agriculture, land-use change, urban planning, water management, forest monitoring, soil quality, and natural protection services;

- the Copernicus Security Service supports border and maritime surveillance and support for EU peace-keeping efforts;

- the Copernicus Emergency Management Service (CEMS) supports the management of disaster emergency situation like floods, forest fires and earthquakes and contributes to humanitarian crises;

- the Copernicus Climate Change Service (C3S) provides data across all the previous themes. It offers authoritative, quality-assured information about the past and current states of the climate in Europe and worldwide, also with seasonal forecasts and climate projections.

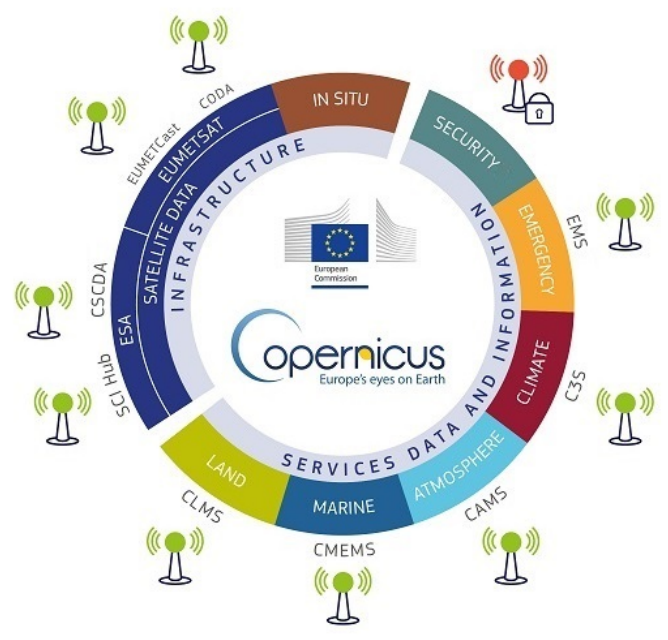

Figure 1. Copernicus Infrastructure and Services (Copernicus, 2021a)

Data belonging to these services covers the European countries or the whole world. The infrastructure is composed of the Satellite data and the in situ component. The satellite acquisitions are developed and managed by the European Space Agency (ESA), combining the European satellite called Sentinels and the contributing missions by third party satellites. The missions are divided into five Mission Groups (Access, 2021), based on the mission type (SAR, Optical, Atmospheric) and on the resolution for the Optical and Atmospheric ones.

The Sentinels family is composed of 6 missions, 5 of which are actually in orbit, each of which is based on two satellites to fulfil revisit time and coverage requirements. These missions carry multiple technologies, like radar and multi-spectral imaging instruments for land, ocean and atmosphere monitoring. The characteristics of the different Sentinel satellites are shown in Table 1. Sentinel-1 provides radar imaging on a polar orbit, allweather, day-and-night for land and ocean services. Sentinel-2 delivers high-resolution multispectral optical imagery for monitoring land. Sentinel-3 provides high-accuracy optical, radar and altimetry data to measure sea-surface topography, sea- and land-surface temperature, ocean and land colour. Sentinel-5 Precursor mission provides data about multiple different gases present in the atmosphere. Finally, Sentinel-6 provides radar altimetry data to measure the sea-surface height in the whole world. The Sentinel-4 and Sentinel-5 missions are in plan in the following years and will provide data on the composition of the atmosphere from a geostationary orbit and a polar orbit.

\begin{tabular}{|l|l|l|l|}
\hline Sentinel & $\begin{array}{l}\text { Spatial } \\
\text { Resolution } \\
\text { meters } 40\end{array}$ & $\begin{array}{l}\text { Revisit } \\
\text { time }\end{array}$ & Stays \\
\hline 1 & $\begin{array}{l}10-5 \text { satellites } \\
\text { meters }\end{array}$ & 5 days & $\begin{array}{l}2 \text { satellites } \\
\text { in orbit }\end{array}$ \\
\hline 2 & $\begin{array}{l}300-1.200 \\
\text { meters }\end{array}$ & $\begin{array}{l}\text { less than 2 } \\
\text { days }\end{array}$ & $\begin{array}{l}2 \text { satellites } \\
\text { in orbit }\end{array}$ \\
\hline 3 & $\begin{array}{l}8 \text { kilometres } \\
\text { 1 hour }\end{array}$ & $\begin{array}{l}\text { First launch } \\
\text { in 2023 }\end{array}$ \\
\hline 4 & $\begin{array}{l}7-68 \text { kilo- } \\
\text { metres }\end{array}$ & 1 day & $\begin{array}{l}\text { 1 satellite in } \\
\text { orbit }\end{array}$ \\
\hline $5 p$ & $\begin{array}{l}7.5-50 \\
\text { kilometres }\end{array}$ & 1 day & $\begin{array}{l}\text { First launch } \\
\text { in 2023 }\end{array}$ \\
\hline 5 & 300 meters & 10 days & $\begin{array}{l}1 \text { satellite in } \\
\text { orbit }\end{array}$ \\
\hline 6 & &
\end{tabular}

Table 1. Sentinel Family satellites attributes

In addition to the Sentinel family, the Contributing Missions provide data from ESA and EUMETSAT, from space agencies of their Member States, and international third party mission operators. The Contributing Missions play a crucial role as they are essential to provide complementary data which complete the whole range of observation required.

The other important component is the in situ segment (Copernicus, 2021b) provided by the Member States agency. In situ data are observations from ground-based, sea-borne and airborne sensors, but also geospatial reference and ancillary data belonging to this component. The in situ component is fundamental for validation and calibration of the satellite data, thus allowing the Copernicus products to be reliable information services. Those data are licensed for use and integration in Copernicus.

\section{STATE OF THE ART OF THE ENERGY CHALLENGE}

As said, European Green Deal and climate-neutrality goals represent a big challenge for the energy sector. Long-term policies, based on energy scenarios, are necessary to drive this transition, towards a decarbonized system. Several aspects are involved which require deep investigation and analysis such as renewable resource potential, energy demand and efficiency, power plant emissions and energy system flexibility (sectors integration, multi-energy systems, storage). As regards renewable resources, energy potential estimation, based on resource availability, is a key element for the identification of suitable sites. Moreover, analyzing the integration of renewable plants in the territory, taking into account areas of environmental or historical interest and possible competition among different land uses (e.g. energy vs agricultural use) could support the identification of actually available surfaces, above all for large photovoltaic plants. 
Geographic Information System (GIS) analysis can support studies on most of the cited aspects as well as energy scenarios implementation, in order to steer national policies. As an example, a GIS-Based methodology for evaluating the windenergy potential of Andalusia (Spain) is presented in (DíazCuevas, 2018). The study proposed by (Ghorbani et al., 2019) focuses the attention on potential sites for pumped hydro energy storage and illustrates a GIS-based method applied on a case study in Iran. In another case study localized in Greece (Vasileiou et al., 2017), a GIS coupled with multi-criteria decision analysis was used for site selection of hybrid offshore wind and wave energy systems. A GIS-based multi-criteria approach was also developed in the study (Miller and Li, 2014), with the aim to identify the areas best suited to wind energy development in Northeast Nebraska. GIS based models have been used also to assess energy demands and consumptions, generally at urban scale. For example, two applications focused on building energy consumptions (Groppi et al., 2018) and electrical consumptions (Santoli et al., 2019). Finally, the focus is moved to the optimisation of flexibilisation technologies in urban areas (Alhamwi et al., 2017). These studies are often focused on a national or subnational scale and the use of detailed and specific data from local public offices or research institutes is, thus, crucial (Miller and Li, 2014).

From the above cited examples, it is evident that accurate and flexible geospatial information constitutes a priority when dealing with different aspects of the energy system which could be explored at many geospatial scales. Issues of data concerning the energy system are mainly related to their production and diffusion. It is not unusual to find data arranged at a fixed time or provided in tabular format, thus hampering both spatial and multi-temporal analysis. When spatialized, this data often lacks a multiscale connotation, as they can be characterized by a high specificity on a very local scale, or by a higher degree of generalization on a very large scale. This issue can make data integration from multiple sources and topics extremely complex for analysis related to renewable resources development scenarios.

Finally, some statistical data concerning the energy system are only provided by institutional entities after formal request and can not be directly downloaded. This issue can make data analysis less immediate and more time consuming.

\section{COPERNICUS DATASET FOR THE ENERGY CHALLENGE}

Copernicus data can provide considerable advantages for energy systems analysis. First, data provided by Copernicus services are mainly produced and shared through the most common geospatial data formats. Thanks to the flexibility of satellite acquisitions in terms of geographic coverage, spatial detail and revisit time, multi-scale and multi-temporal analysis can be performed in most cases and can be adapted to a variety of topics. Copernicus data are also able to provide additional information which can be hardly retrieved without satellite images (e.g. classifications of very specific features), thus enriching the range of possible analysis to perform. Besides, satellite-derived data can be integrated with in-situ data through the available ground component for more detailed analysis.

Finally, the vast majority of data/information delivered by Copernicus is made available and accessible to any citizen and any organisation around the world on a free, full, and open basis through websites or platforms of the specific service. Datasets which can be considered useful for the energy challenge mainly belong to CAMS, CMEMS, CLMS and C3S Copernicus services. Datasets provided in Copernicus Security Service and CEMS are not related to energy, thus they will not be treated in this paper.

\subsection{Analysis technique}

Within this work, the products offered by Copernicus services will be analysed mainly in terms of:

- Geospatial characteristics;

- Temporal aspects.

In particular, the two attributes can be expressed in terms of:

- The coverage that influences the possibility of providing the analysis in a specific area of the world or a specific instant;

- The resolution which defines the minimum scale of analysis or for the calibration of the model.

Other characteristics of interest are the file format and the availability of APIs (Application Programming Interface) or dedicated tools for data analysis. These factors are critical for the definition of datasets usability. The APIs are an important advantage for creating automatic processes that combine and analyse data in quasi-real time in forecast models. Besides, the use of APIs allows the process of the data in a smarter way.

The variable format depends on the variable itself, instead of the APIs and the dedicated tools that are depending only on the Copernicus Service of reference. The dataset provided in the $\mathrm{C} 3 \mathrm{~S}$ and the CAMS could be managed with APIs in their data store, the Climate Data Store (CDS) and the Atmosphere Data Store (ADS). The library of the API is the same and it is documented in the forum. The C3S also provides the CDS toolbox; it could be used to analyse and visualise the data using Python without download. As reported in the ADS forum, the toolbox will soon be available for the CAMS data. Other dedicated tools could be found in the CLMS. It provides two powerful instruments that could be used for the analysis: interactive notebooks and virtual machine desktop. The services are provided through the Terrascope platform. The notebooks are helpful in creating small demos of the products without downloading. The dataset could be managed and visualised using the most common programming language such as Python and R. Virtual machines are more powerful tools that could be used as a desktop computer. Different open source tools for the management of geospatial data are already installed in them, like SNAP and QGIS.

\subsection{Analysed datasets in the Copernicus Services}

Products of interest for the energy challenge are reported in Table $2 \mathrm{a}$ and $2 \mathrm{~b}$, together with their associated Copernicus Service and the dataset name for each variable of interest. The topic and the Energy resource columns refer to the field of application of the variable. Datasets are mainly related to resources estimation, demand estimation, plants localisation or forecast.

The datasets regarding the resources could be further divided according to the different energy sources: wind, sun, biomass, sea currents and waves, geothermal and hydropower. Some of 
the variables could be used for different topics and for the estimation of different resources. Multiple datasets that provide an estimation of resource are available in the Dataset "ERA5 hourly data on single levels from 1979 to present" in the C3S (Hersbach et al., n.d.). The data are the fifth generation of the European Center Medium Weather Forecast (ECMWF) reanalysis for the global climate and weather. The variables are available globally and provided in a grid format with a spatial resolution of $1 / 4$ degree. It corresponds to $27 \mathrm{~km}$ in longitude and $20 \mathrm{~km}$ at the Italian latitude.

The variables "Actual Weather conditions" and "Cloud-free conditions" are provided into the dataset "CAMS solar radiation time series" (Copernicus Atmosphere Monitoring Service, 2021). They are also provided as aggregated data to 15 minutes, one hour, one day and one month. As reported in Table 2a, the "Cloud-free conditions" covers mainly Europe and Africa $\left(-66^{\circ}\right.$ to $66^{\circ}$ in both latitude and longitude); this is due to the use of the data of the Meteosat satellite to estimate cloud information, so the data are available only in its field of view. The data are provided in punctual format, with an interpolation of $3-5 \mathrm{~km}$ to the point requested. It is possible to download only one location per request; this operation could be improved using the API of the ADS. It is possible to create a Python script that allows the download of multiple files for the area of interest and then combine them locally.

The Ocean and Sea Physic Reanalysis datasets are split into different areas of interest depending on the portion of the different European seas and oceans. The products are available for the Mediterranean Sea (Simoncelli et al., 2019), the Black Sea (Lima et al., 2020), the Baltic Sea (Copernicus Marine Environment Monitoring Service, 2021c), the Atlantic-Iberian Biscay Irish Ocean (Copernicus Marine Environment Monitoring Service, 2021b) and the Atlantic-European North West Shelf Ocean (Copernicus Marine Environment Monitoring Service, 2021a). The variables are provided at different layers according to the different levels of depth. The data are also aggregated with daily-mean and monthly-mean, but they are not available for all the products.

Table $2 \mathrm{a}$ also reports the use of different land cover products which can be useful for rough biomass estimation. For an accurate biomass estimation more detailed data are needed, as multi-temporal crop type maps. Land cover data could also be used for the identification of suitable areas for power plants installation particularly in the case of large photovoltaic plants. Planning of new plants should follow the principle of exploiting already urbanized areas (e.g. industrial areas, brownfields). Alternatively, in the semi-urban areas, the localisation of the plants could be based on the combination with the agricultural fields.

The variables describing the future climate project could also be used for resources long term planning and for energy system development scenarios. As an example, in the SWICCA project (Copernicus Climate Change Service, 2021c) data of C3S were combined with local observations for the study of the evolution of the hydropower sector in an area of interest. Also, historical data of C3S were used for the calibration of the model. This type of analysis shows how the combination of satellite data, local sensors and future scenarios could be used to plan and manage a hydropower reservoir.

\subsection{Other useful dataset in the Copernicus Infrastructure}

Some other products could be estimated directly from satellite data for topics connected with renewable energy sources. Those variables are produced by satellite Sentinel family and European Space Agency (ESA) missions.

The estimation of the geothermal resources could also be done by satellite acquisition. In collaboration with the International Renewable Energy Agency (IRENA), the ESA tested this approach in 2015; later, more advanced studies have been done (Pastorutti and Braitenberg, 2019). The research used gravity measurements from the Gravity Field and Steady-State Ocean Circulation Explorer (GOCE) mission to identify areas with geothermal potential. The result shows the applicability of the methodology, but ground surveys and seismic measurements are still needed to determine the exact points for energy extraction.

Another field of use of satellite data could be the estimation of the pollution due to the emission of the plants. The historical data could be useful to estimate the emission of fossil fuel plants and the possible reduction of carbon emission. The European Space Agency (ESA) has a mission designed to collect air monitoring data (Copernicus, 2021c). The mission launched in 2017 the satellite Sentinel 5 Precursor, also known as Sentinel-5P. The instruments present on the satellite could map multiple different gases. The data of interest are level-2, in particular the total column of carbon monoxide (CO), formaldehyde (HCHO), nitrogen dioxide (NO2), ozone (O3), sulphur dioxide (SO2) and methane (CH4). The products of Sentinel-5P are available in different processing levels: near-real-time (NRL), offline (OFFL) and reprocessing. Almost all the data of interest are available within 3 hours after the sensing as NRL with a daily temporal resolution. The methane and the corrected nitrogen dioxide are available within five days. The reprocessed data are available without time constraints for all the data described, particularly when major product upgrades are considered necessary. Those data are available globally with a spatial resolution that varies in time. Before August 2019, the resolution was $7.0 \times 7.0 \mathrm{~km}$; now, it is reduced to $7.0 \times 5.5 \mathrm{~km}$. The data are not present in the Copernicus Services but are available in the Copernicus Open Access Hub. The platform provides the download of the data of the Sentinel-5P in a dedicated portal. The data are provided in NetCDF format.

\section{COPERNICUS DATA FOR EMERGING ENERGY THEMES}

Among the emerging research themes related to energy, the Water, energy and food nexus (meaning the interdependencies between water, energy and food) is commanding increasing attention. As reported by the Food and Agriculture Organization (FAO, 2014), "in order to assess nexus interactions, reliable, pertinent and timely data is needed. Satellite observations, combined with in-situ data, provide a unique source of consistent information about the natural environment, on which we rely to produce water, energy and food".

In this context, a very interesting recent technological solution is represented by agrivoltaic. Agrivoltaic is a hybrid agriculture-energy system in which agricultural crops are grown at the partial shade of the solar infrastructure (BarronGafford et al., 2019). In general terms, an agrivoltaic plant 
could compensate for the impacts of extreme weather conditions by reducing water requirement, increasing both crop yield and efficiency of photovoltaic energy production. Besides, in specific conditions it could generate indirect benefits, supplying for ecosystem services (e.g. favourable conditions for pollinating insects).

Since agrivoltaic is an innovative solution, further investigations are desirable to test and estimate the actual benefits and their significance especially in relation to crop type and crop environmental conditions. Concerning data requirement, land use and in particular agricultural related data (e.g. crop type and evapotranspiration estimate) could be used to perform analysis on suitable sites for agrivoltaic plants. In particular, geospatial data could support the identification of areas where the presence of an agrivoltaic system could be particularly effective from a food-energy-water nexus perspective, as areas at risk of water and climate stress, or agricultural land under high potential risk of abandonment, where the combined value of energy and agricultural production could make their recovery economically sustainable. Satellite remote sensing is particularly useful to this aim as it can capture spatial and temporal dynamics of many environmental phenomena. Corine land cover data together with phenology and productivity data (which will be available for public use at the end of July 2021) derived from Sentinel-2 satellite acquisitions are already part of the CLMS and could be combined for retrieving information related to crop conditions. Another key parameter to provide inputs for agriculture and related water resources management is Evapotranspiration (ET) and satellite remote sensing of evapotranspiration is an essential part of the global observation system. Within this context ESA has funded the Sentinels for Evapotranspiration (Sen-ET) project (Copernicus, 2021d) with the aim of developing an optimal methodology for estimating ET at fine spatial scale, based on Sentinel 2 and Sentinel 3 satellites observations. At the moment, results of this project are not part of Copernicus services.

\section{CONCLUSION}

Significant challenges will interest the energy sector in the following years. As reported, the actual methodologies used present multiple issues on the different aspects of the data. The use of Copernicus data could provide a solution for multiple of the issues. Differently from the previous dataset used, the satellite data, thanks to their flexibility, allows performing multiscale and multi-temporal analysis. This is fundamental for creating tools and models for the planning and management of renewable power plants.

Finally, the Copernicus data will also be fundamental for the emerging themes in the sector. The challenge of the waterenergy-food nexus will need the usage of the new methodologies as a source of consistent information on the natural environment.

\section{REFERENCES}

Access, C. S. C. D., 2021. Contributing missions. https: //spacedata.copernicus.eu/web/cscda/data-offer/missions. [Online; accessed 15-June-2021].

Alhamwi, A., Medjroubi, W., Vogt, T., Agert, C., 2017. GISbased urban energy systems models and tools: Introducing a model for the optimisation of flexibilisation technologies in urban areas. Applied Energy, 191(C), 1-9.

Barron-Gafford, G., Pavao-Zuckerman, M., Minor, R., Sutter, L., Barnett-Moreno, I., Blackett, D., Thompson, M., Dimond, K., Gerlak, A., Nabhan, G., Macknick, J., 2019. Agrivoltaics provide mutual benefits across the food-energy-water nexus in drylands. Nature Sustainability, 2(9), 848-855.

Buchhorn, M., Smets, B., Bertels, L., De Roo, B., Lesiv, M., Tsendbazar, N. E., Herold, M., Fritz, S., 2020. Copernicus global land service: Land cover $100 \mathrm{~m}$ : collection 3: epoch 2019: Globe. https://zenodo.org/communities/ copernicus-land-cover/. [Online; accessed 15-June-2021].

Copernicus, 2021a. Conventional data access hubs. https://www.copernicus.eu/en/accessing-data-where-and-how/ conventional-data-access-hubs. [Online; accessed 15-June2021].

Copernicus, 2021b. In situ component. https://insitu. copernicus.eu/. [Online; accessed 15-June-2021].

Copernicus, 2021c. Sentinel 5p mission. https://sentinel.esa.int/ web/sentinel/missions/sentinel-5p. [Online; accessed 15-June2021].

Copernicus, 2021d. Sentinels for evapotranspiration (sen-et) project. https://www.esa-sen4et.org/. [Online; accessed 15June-2021].

Copernicus Atmosphere Monitoring Service, 2021. Cams solar radiation time-series. https://ads.atmosphere.copernicus. eu/cdsapp\#!/dataset/cams-solar-radiation-timeseries. [Online; accessed 15-June-2021].

Copernicus Climate Change Service, 2021a. Climate and energy indicators for europe from 1979 to present derived from reanalysis. doi.org/10.24381/cds.4bd77450. [Online; accessed 15-June-2021].

Copernicus Climate Change Service, 2021b. Climate and energy indicators for europe from 2005 to 2100 derived from climate projections. doi.org/10.24381/cds.f6951a62. [Online; accessed 15-June-2021].

Copernicus Climate Change Service, 2021c. Service for water indicators in climate change adaptation (swicca). https://swicca. eu/. [Online; accessed 15-June-2021].

Copernicus Land Monitoring Service, 2021a. Coastal zones. https://land.copernicus.eu/local/coastal-zones. [Online; accessed 15-June-2021].

Copernicus Land Monitoring Service, 2021b. Corinne land cover. https://land.copernicus.eu/pan-european/ corine-land-cover. [Online; accessed 15-June-2021].

Copernicus Marine Environment Monitoring Service, 2021a. Atlantic-european north west shelfocean physics reanalysis. https://resources.marine. copernicus.eu/?option=com_csw\&view=details\&product_id= NWSHELF_MULTIYEAR_PHY_004_009. [Online; accessed 15-June-2021].

Copernicus Marine Environment Monitoring Service, 2021b. Atlantic-iberian biscay irish-ocean physics reanalysis. https://resources.marine.copernicus.eu/?option=com_csw\& view=details\&product_id=IBI_MULTIYEAR_PHY_005_002. [Online; accessed 15-June-2021]. 
Copernicus Marine Environment Monitoring Service, 2021c. Baltic sea physics reanalysis. https://resources.marine. copernicus.eu/?option=com_csw\&view=details\&product_id $=$ BALTICSEA_REANALYSIS_PHY_003_011. [Online; accessed 15-June-2021].

Copernicus Marine Environment Monitoring Service, 2021d. Global ocean gridded 14 sea surface heights and derived variables. https://resources.marine. copernicus.eu/?option=com_csw\&view=details\&product_id $=$ SEALEVEL_GLO_PHY_L4_NRT_OBSERVATIONS_008_046. [Online; accessed 15-June-2021].

Díaz-Cuevas, P., 2018. GIS-Based Methodology for Evaluating the Wind-Energy Potential of Territories: A Case Study from Andalusia (Spain). Energies, 11(10). https://www.mdpi. com/1996-1073/11/10/2789.

FAO, 2014. The water-energy-food nexus. http://www.fao.org/ 3/bl496e/bl496e.pdf.

Ghorbani, N., Makian, H., Breyer, C., 2019. A GIS-based method to identify potential sites for pumped hydro energy storage - Case of Iran. Energy, 169(C), 854-867. https://ideas.repec. org/a/eee/energy/v169y2019icp854-867.html.

Groppi, D., Santoli, L., Cumo, F., Astiaso Garcia, D., 2018. A GIS-based model to assess buildings energy consumption and usable solar energy potential in urban areas. Sustainable Cities and Society, 40.

Hariss, S., Saifaoui, D., Hilmi, K., Lilane, A., Sossy, V. D., 2020. Exploitation of the Moroccan maritime potential in tidal energy. Materials Today: Proceedings, 30, 984-986. https://www.sciencedirect.com/science/article/pii/ S2214785320329849. International Conference on Renewable Energy and Applications (ICREA 19).

Hersbach, H., Bell, B., Berrisford, P., Biavati, G., Horányi, A., Muñoz Sabater, J., Nicolas, J., Peubey, C., Radu, R., Rozum, I., Schepers, D., Simmons, A., Soci, C., Dee, D., Thépaut, J.-N., n.d. Era5 hourly data on single levels from 1979 to present. doi. org/10.24381/cds.adbb2d47. [Online; accessed 15-June-2021].

Lima, L., Aydogdu, A., Escudier, R., Masina, S., Ciliberti, S., Azevedo, D., Peneva, E., Causio, S., Cipollone, A., Clementi, E., Cretí, S., Stefanizzi, L., Lecci, R., Palermo, F., Coppini, G., Pinardi, N., Palazov, A., 2020. Black sea physical reanalysis. https://doi.org/10.25423/CMCC/ BLKSEA_MULTIYEAR_PHY_007_004. [Online; accessed 15June-2021].

Miller, A., Li, R., 2014. A Geospatial Approach for Prioritizing Wind Farm Development in Northeast Nebraska, USA. ISPRS International Journal of Geo-Information, 3(3), 968-979. https: //www.mdpi.com/2220-9964/3/3/968.

Moreno-Garcia, I. M., López-Luque, R., Varo-Martínez, M., Fernández-Ahumada, L. M., Ramírez-Faz, J. C., de la Torre, F. C., 2019. An approach for the solar energy assessment using weather medium-range forecasting. 2019 IEEE International Conference on Environment and Electrical Engineering and 2019 IEEE Industrial and Commercial Power Systems Europe (EEEIC / I CPS Europe), 1-5.

Pastorutti, A., Braitenberg, C., 2019. A geothermal application for GOCE satellite gravity data: modelling the crustal heat production and lithospheric temperature field in Central Europe. Geophysical Journal International, 219(2), 1008-1031.
Santoli, L., Mancini, F., Garcia, D., 2019. A GIS-based model to assess electric energy consumptions and usable renewable energy potential in Lazio region at municipality scale. Sustainable Cities and Society, 46, 101413.

Simoncelli, S., Fratianni, C., Pinardi, N., Grandi, A., Drudi, M., Oddo, P., Dobricic, S., 2019. Mediterranean sea physical reanalysis. https://doi.org/10.25423/MEDSEA REANALYSIS_PHYS_006_004. [Online; accessed 15-June2021].

Vasileiou, M., Loukogeorgaki, E., Vagiona, D. G., 2017. GISbased multi-criteria decision analysis for site selection of hybrid offshore wind and wave energy systems in Greece. Renewable and Sustainable Energy Reviews, 73(C), 745-757. https://ideas. repec.org/a/eee/rensus/v73y2017icp745-757.html. 


\begin{tabular}{|c|c|c|c|c|c|c|c|c|c|c|c|}
\hline 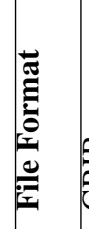 & 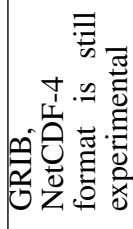 & 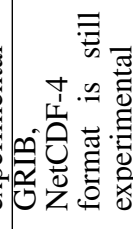 & 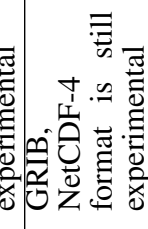 & 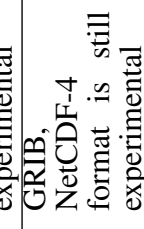 & 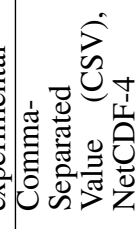 & 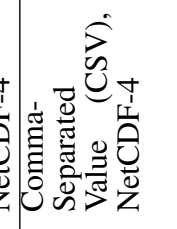 & 暠 & 场 & 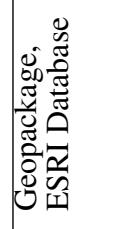 & $\frac{1}{4}$ & $\begin{array}{l}7 \\
\frac{1}{1} \\
0 \\
0 \\
0 \\
0\end{array}$ \\
\hline 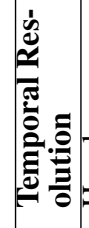 & 希 & $\frac{\overrightarrow{3}}{\bar{\Xi}}$ & $\overrightarrow{\mathrm{B}}$ & 恋 & 曽 & 羙 & - & - & - & $\overrightarrow{\bar{\Xi}}$ & 름 \\
\hline 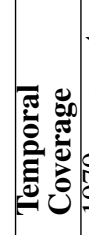 & 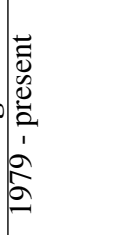 & 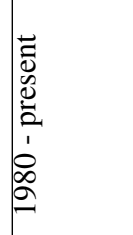 & 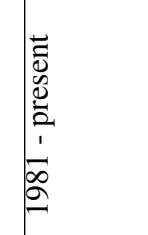 & 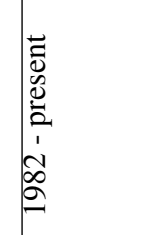 & 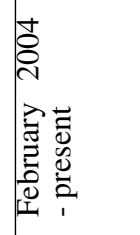 & 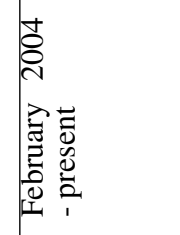 & 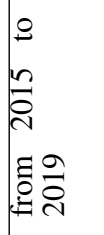 & 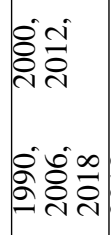 & $\mid \begin{array}{l}\infty \\
\infty \\
\infty\end{array}$ & 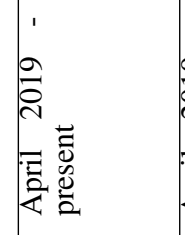 & 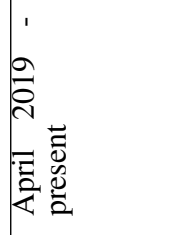 \\
\hline 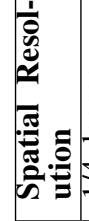 & 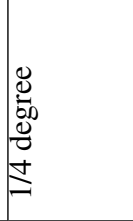 & 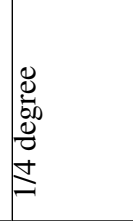 & 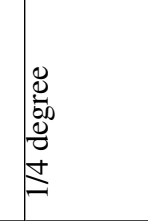 & 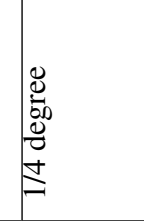 & 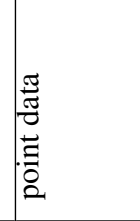 & 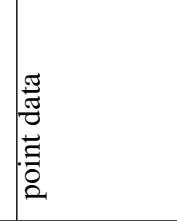 & 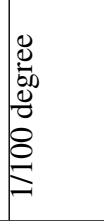 & 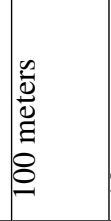 & 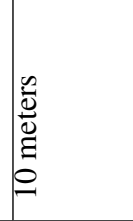 & 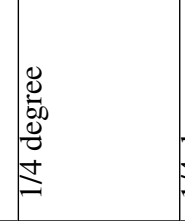 & 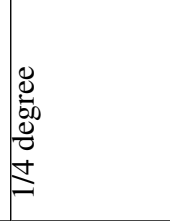 \\
\hline 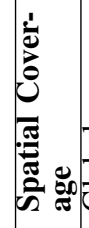 & \begin{tabular}{|l} 
\\
0 \\
$\frac{0}{0}$ \\
0
\end{tabular} & $\begin{array}{l}\bar{\pi} \\
\frac{0}{0} \\
0\end{array}$ & $\begin{array}{l}\overline{0} \\
\frac{0}{0} \\
\end{array}$ & $\begin{array}{l}\bar{\pi} \\
\frac{0}{0} \\
0\end{array}$ & $\begin{array}{l}\bar{\pi} \\
0 \\
0 \\
\end{array}$ & 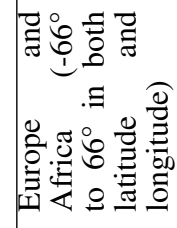 & 0 & 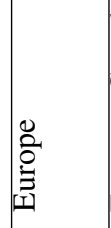 & 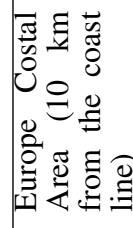 & $\begin{array}{l}\bar{\pi} \\
0 \\
0 \\
0 \\
0\end{array}$ & $\begin{array}{l}\bar{\pi} \\
\frac{0}{0} \\
0\end{array}$ \\
\hline 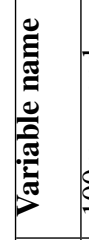 & 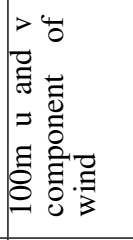 & 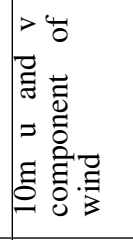 & 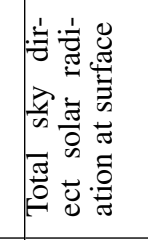 & 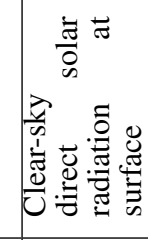 & 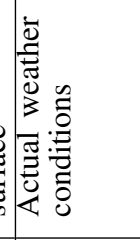 & 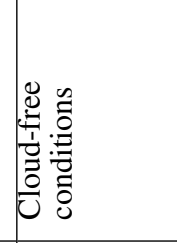 & 1 & - & K & 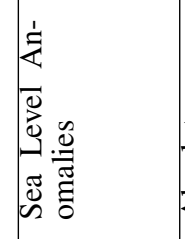 & 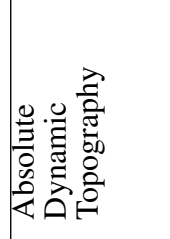 \\
\hline 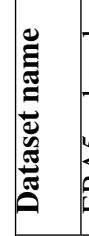 & 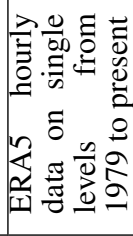 & 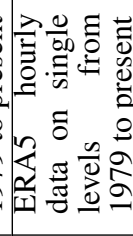 & 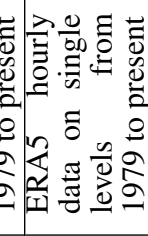 & 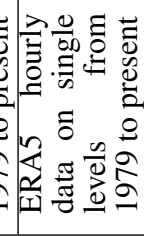 & 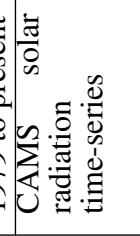 & 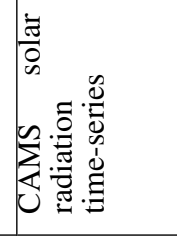 & 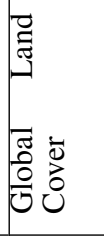 & 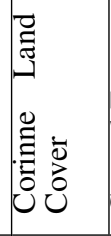 & 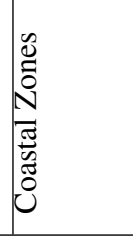 & 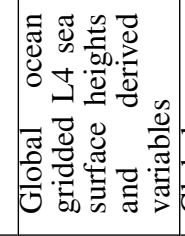 & 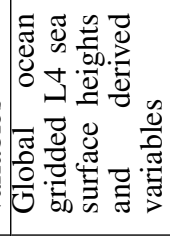 \\
\hline 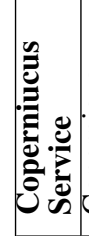 & 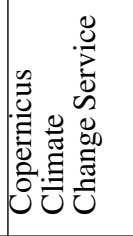 & 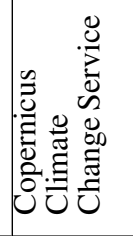 & 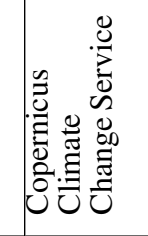 & 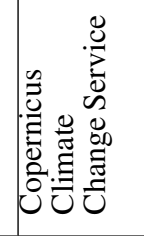 & 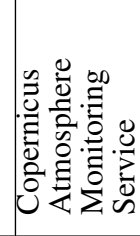 & 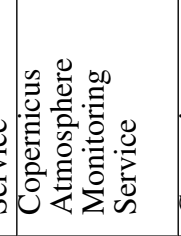 & 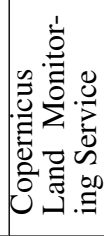 & 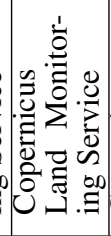 & 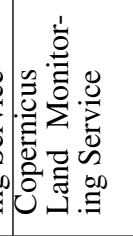 & 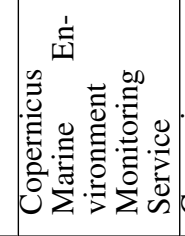 & 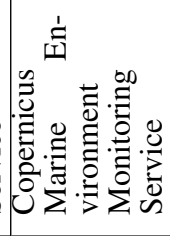 \\
\hline 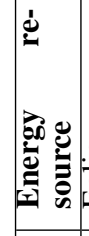 & $\begin{array}{l}0 \\
0 \\
0 \\
\\
\end{array}$ & : & 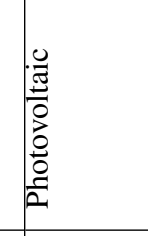 & 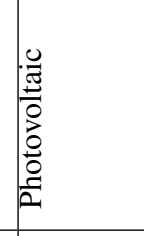 & 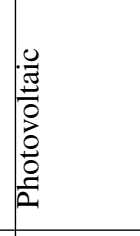 & $\begin{array}{l}\frac{0}{\pi} \\
\frac{\pi}{0} \\
0 \\
0 \\
0 \\
\frac{0}{2} \\
\frac{1}{2}\end{array}$ & 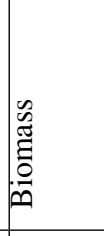 & 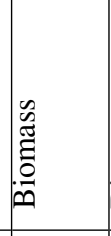 & 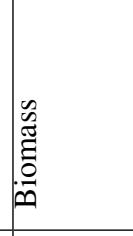 & 竞 & 节 \\
\hline 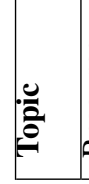 & 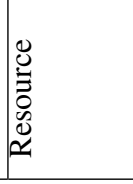 & 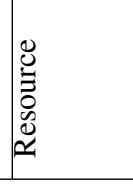 & 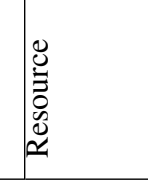 & 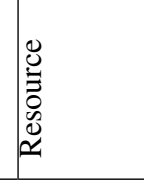 & 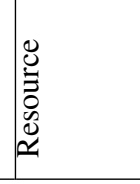 & 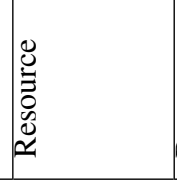 & 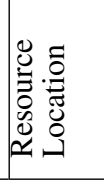 & 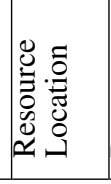 & 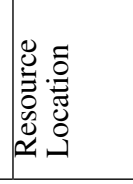 & 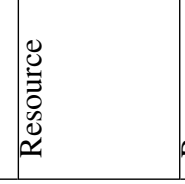 & 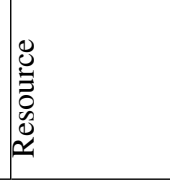 \\
\hline
\end{tabular}

Table 2a. Datasets of interest for the energy challenge 


\begin{tabular}{|c|c|c|c|c|c|c|}
\hline 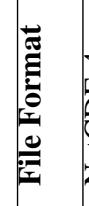 & 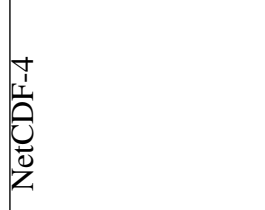 & 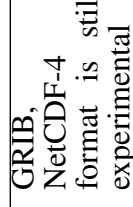 & 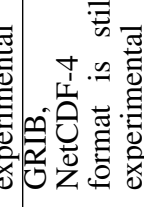 & 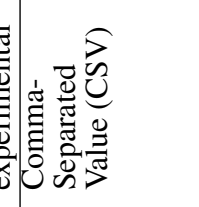 & 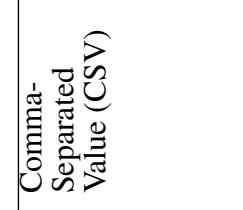 & 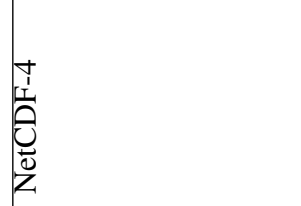 \\
\hline 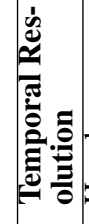 & 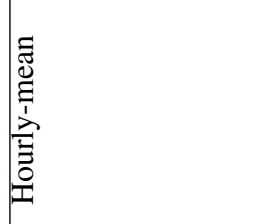 & $\vec{i}$ & 咅 & 﨎 & 를 & 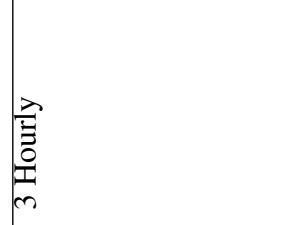 \\
\hline 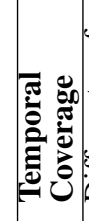 & 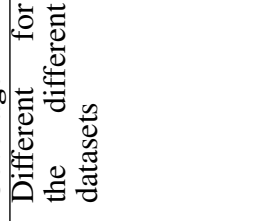 & 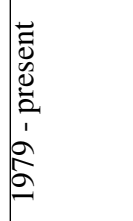 & 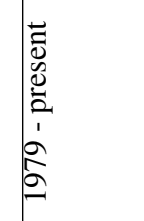 & 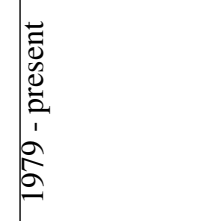 & $\begin{array}{l}8 \\
\frac{8}{1} \\
1 \\
\stackrel{2}{2} \\
i\end{array}$ & $\begin{array}{l}8 \\
\stackrel{8}{1} \\
1 \\
\stackrel{2}{2} \\
i\end{array}$ \\
\hline 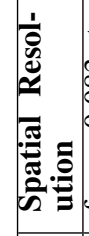 & $\begin{array}{ll}0 & \\
0 & 0 \\
n & 0 \\
0 & 0 \\
0 & 0 \\
0 & 0 \\
0 \\
0 \\
0 \\
0 \\
0 & 0 \\
0 & 0\end{array}$ & 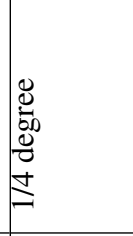 & 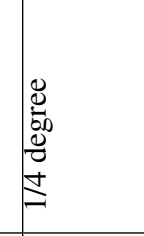 & 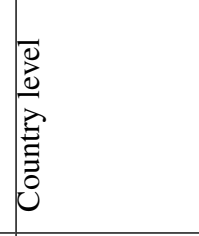 & 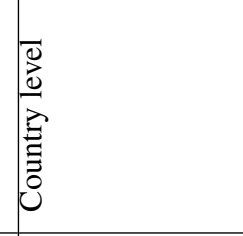 & 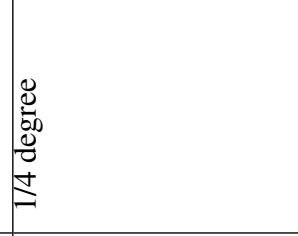 \\
\hline 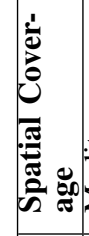 & 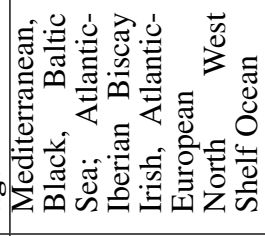 & & $\begin{array}{l}\bar{\pi} \\
\frac{0}{0} \\
\end{array}$ & | & 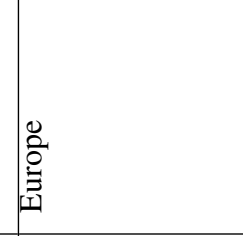 & 苋 \\
\hline 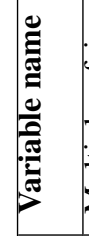 & 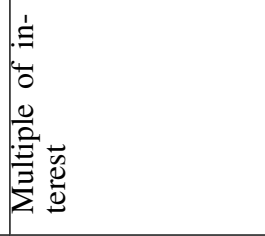 & 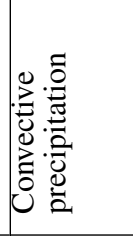 & 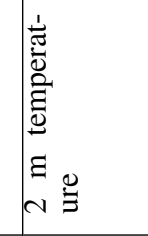 & 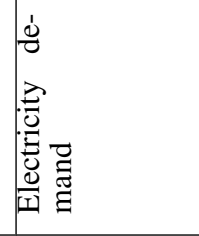 & 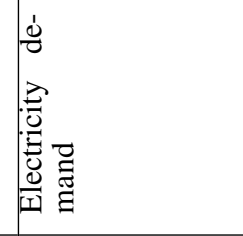 & 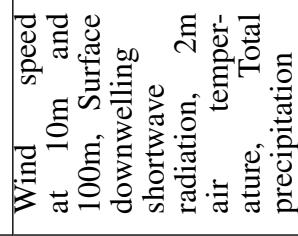 \\
\hline 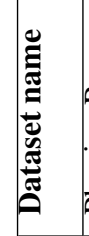 & 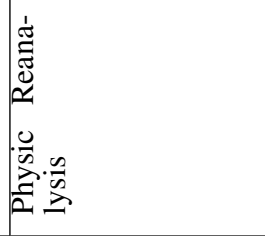 & 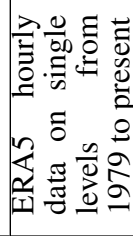 & 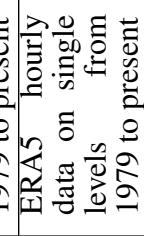 & 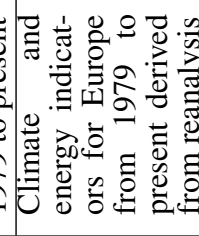 & 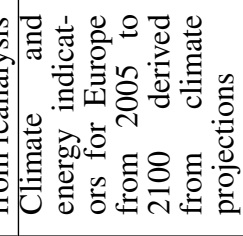 & 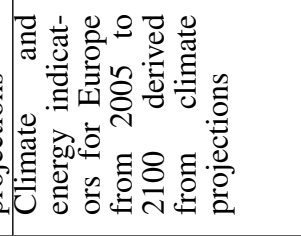 \\
\hline 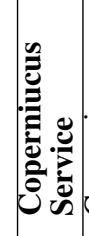 & 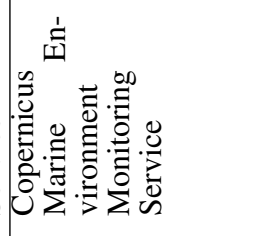 & 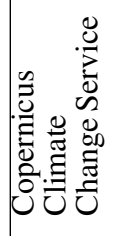 & 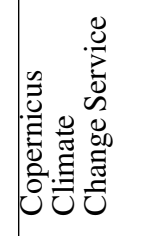 & 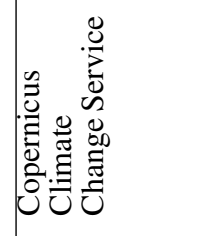 & 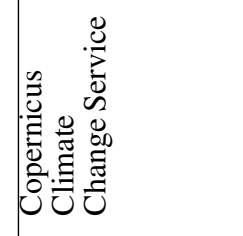 & 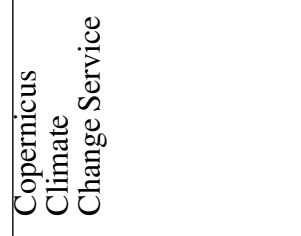 \\
\hline 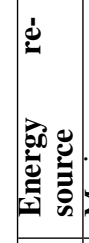 & 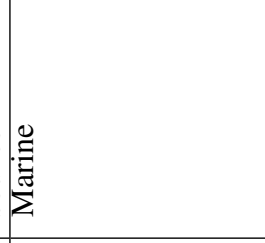 & - & - & 人 & - & - \\
\hline 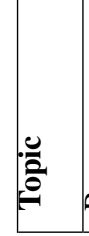 & 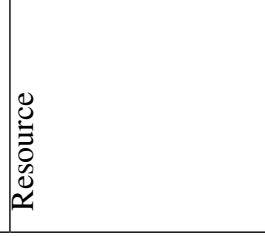 & 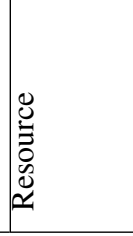 & 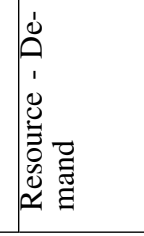 & 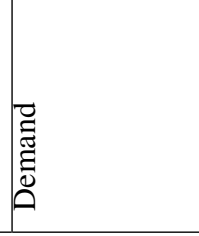 & 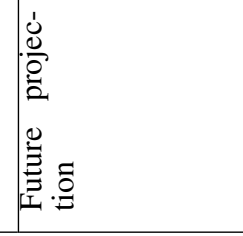 & 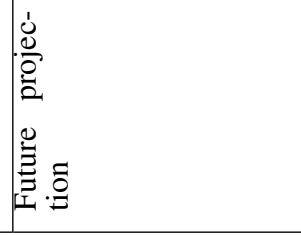 \\
\hline
\end{tabular}

Table 2b. Datasets of interest for the energy challenge 